\title{
PENERAPAN TEKNOLOGI TEPAT GUNA DAN PERBAIKAN MANAJEMEN PRODUKSI UMKM KRUPUK PULI SIDOARJO
}

\author{
Astria Hindratmo', Ong Andre Wahyu Riyanto², Ubaet Tajuddin ${ }^{3}$ \\ ${ }^{1}$ Universitas Wijaya Putra Surabaya \\ ${ }^{2}$ Universitas Wijaya Putra Surabaya \\ ${ }^{3}$ Universitas Wijaya Putra Surabaya
}

astriahindratmo@uwp.ac.id,ongandre@uwp.ac.id, ubet1997@gmail.com

\begin{abstract}
Abstrak
Mitra kegiatan PPM ini yaitu UMKM krupuk Puli terletak di Dusun Kaliwaru Desa Kedung Rejo Kecamatan Jabon Kabupaten Sidoarjo. UMKM Krupuk Puli memiliki beberapa permasalahan yaitu sulitnya menjemur krupuk saat musim hujan sehingga produksi turun. Masalah berikutnya yaitu pengadaan bahan baku tanpa rencana sehingga pembelian seringkali mendadak. Kemudian pada manajemen pemasaran mitra tidak memiliki alternatif memasarkan produk karena selalu mengandalkan pesanan dari para tengkulak yang datang ke rumah. Tujuan dari kegiatan ini yaitu meningkatkan efektivitas produksi dan perbaikan manajemen usaha.Metode penyelesaian masalah yang diberikan pada mitra yaitu pelatihan dan pendampingan. Pelatihan dan pendampingan yang diberikan yaitu terkait pembuatan perencanaan bahan baku yaitu membuatkan daftar rencana kebutuhan bahan baku per 6 bulan. kemudian untuk manajemen pemasaran yaitu membuatkan konsep pemasaran dengan marketing mix 4P (Product, Price, Place, Promotion) \& STP (Segmentation, Targetting, Positioning). Selain itu dibuatkan iklan online melalui akun media sosial untuk memperluas jangkauan pemasaran dan sebagai alternatif pemasaran selain melalui tengkulak. Kemudian mitra dibuatkan desain mesin oven pengering krupuk saat terjadi musim hujan. Hasil dari kegiatan yaitu mitra sudah mampu membuat perencanaan bahan baku yang sistematis, mampu membuat konsep marketing offline maupun online. Kemudian mitra telah memiliki desain mesin oven pengering krupuk yang dapat diaplikasikan saat musim hujan.
\end{abstract}

Kata Kunci : UMKM, pemasaran, mesin pengering krupuk

\section{PENDAHULUAN}

Desa Kedung Rejo Kecamatan Jabon sejak tahun 1976 dikenal sebagai sentra penghasil krupuk. Sebagian besar penduduknya membuat krupuk, sehingga desa Kedung Rejo Kecamatan Jabon Kabupaten Sidoarjo Mendapat Julukan sebagai kampung Krupuk (Bayu, 2013). Desa Kedung Rejo terbagi dalam enam Dusun yaitu Dusun Tungguwulung, Bioro, Kedung bahak, Klutuk, Biting, dan Kaliwaru. Berdasarkan data kelurahan
Kedung Rejo menjelaskan bahwa Dusun Tungguwulung terdapat 21 pengrajin, Dusun Biora 16 Pengrajin, dan Dusun Kaliwaru 10 pengrajin.

Jumlah produksi krupuk di Desa Kedung Rejo tidak kurang dari 5000 lembar krupuk di produksi warga setiap harinya dan sekitar 500 ton krupuk berbagai jenis berhasil diproduksi warga desa Kedung Rejo tiap bulannya. Jenis krupuk yang di produksi yaitu krupuk ikan, krupuk puli, krupuk bawang, krupuk musiman. 
Khusus untuk Dusun Kaliwaru pengrajin krupuk puli lebih mendominasi dibandingkan jenis krupuk lainnya.. Rata-rata UMKM krupuk Puli desa Kaliwaru mampu meproduksi 1 kwintal hingga 5 kwintal per hari. Walaupun mampu memproduksi krupuk puli perhari yang cukup banyak, Namun pada kenyataannya dalam produksinya pengrajin di daerah Dusun Kaliwaru memiliki beberapa permasalahan. Permasalahan tersebut menyebabkan usaha krupuk puli di Dusun Kaliwaru mengalami perkembangan yang cukup lambat. Permasalahan pengrajin yaitu pada aspek produksi dan manajemen.

Permasalahan pada aspek produksi yaitu pengrajin tidak mampu menjemur krupuk saat musim hujan karena masih mengandalkan sinar matahari untuk proses pengeringan krupuk sehingga seringkali tidak mampu memenuhi permintaan. Kemudian permasalahan pada aspek manajemen yaitu (1) pengrajin tidak mampu mengatur pengelolaan pengadaan bahan baku. Sehingga sering terjadi kekurangan stock tepung dan pembelian dilakukan secara mendadak yang menyebabkan terjadinya kekurangan modal untuk membeli bahan baku dalam jumlah banyak saat ada pesanan krupuk yang banyak. (2) Pengrajin dalam hal pemasaran hanya mengandalkan pesanan dari tengkulak yang datang ke rumah. Sehingga hal tersebut menyebabkan pengrajin sulit untuk mengembangkan usahanya akibat penjualan krupuk puli yang peningkatannya cukup kecil.

Pada permasalahan pertama mitra terdapat pada aspek produksi yaitu pada proses penjemuran krupuk di musim penghujan. Hingga saat ini mitra masih mengandalkan terik sinar matahari mulai dari pagi hingga siang hari sekitar 6 jam hingga 8 jam. Tentunya hal tersebut akan menjadi masalah saat tidak ada panas sinar matahari dan selain itu waktu proses penjemuran yang cukup lama sehingga kurang efisien dalam hal waktu. Sehingga dalam proses ini dibutuhkan penerapan Teknologi Tepat Guna (TTG) untuk proses pengeringan saat musim hujan dan juga mempercepat waktu pengeringan untuk meningkatkan kapasitas produksi per hari. Pengunaan TTG akan memberikan kemudahan saat produksi karena pada dasarnya di desain secara ergonomis (Nurmianto, 2018). Selain itu juga penerapan TTG akan memberikan dampak terhadap peningkatan produktifitas nilai tambah dari suatu produk (Muhi, 2009).

Pada permasalahan kedua mitra terdapat pada aspek manajemen yaitu manajemen perencanaan bahan baku. Pengrajin tidak mampu merencanakan kebutuhan bahan baku sehingga sering terjadi kekurangan stock tepung dan pembelian dilakukan secara mendadak. Sehingga hal tersebut dapat menyebabkan pengrajin akan kekurangan modal untuk membeli bahan baku apabila pembelian bahan dilakukan dalam jumlah yang banyak. Sehingga dalam permasalahan ini dibutuhkan sistem perhitungan manajemen pengadaan bahan baku dengan menggunakan MPS (Master Production Sheduling) untuk mengetahui penjadwalan produksi sehingga diketahui berapa banyak produk yang akan dibuat dan juga hasil dari MPS tersebut untuk mengetahui jumlah bahan baku yang dibutuhkan dengan menggunakan perhitungan MRP (Material Planning Requirement). Menurut Wahyuni \& Syaichu (2015), untuk mengadakan kegiatan produksi agar berjalan dengan lancar, maka harus tersedia bahan baku yang baik dan sesuai dengan kebutuhan produksi perusahaan.

Pada permasalahan ketiga mitra juga pada aspek manajemen yaitu manajemen pemasaran. Dimana pemasaran hanya mengandalkan pesanan dari tengkulak yang datang ke rumah. Sehingga hal tersebut mengakibatkan pengrajin krupuk sangat tergantung dengan permintaan tengkulak dan jumlah produksi sangat ditentukan oleh permintaan tengkulak. Selain itu juga pengrajin akan terjadi penumpukan stock krupuk apabila tidak ada permintaan dari tengkulak dan juga usaha yang dijalankan oleh pengrajin krupuk sulit untuk berkembang. Maka dari itu dibutuhkan kemampuan untuk merancang konsep pemasaran baik pemasaran offline dengan konsep marketing mix dan juga merancang STP (Segmentation, targeting, positioning). Selain itu juga dibutuhkan pemasaran secara online untuk memperluas area pemasaran dengan media sosial. Menurut Kotler dan keller (2009) menjelaskan bahwa pemasaran merupakan suatu fungsi organisasi dan juga merangkai proses dalam menghasilkan, mengkomunikasikan, hingga memberi nilai terhadap pelanggan untuk tujuan menguntungkan suatu organisasi serta stakeholder.

$$
\text { Teknologi Tepat Guna }
$$


Tujuan dari kegiatan ini yaitu untuk membantu mitra meningkatkan produksi dan penjualan melalui penerapan TTG pada proses produksi dan juga memperbaiki manajemen yaitu manajemen perencanaan pengadaan bahan baku dan juga manajemen pemasaran. Pada penerapan TTG yaitu dengan alat berupa mesin oven atau pengering krupuk. Sedangkan pada manajemen pemasaran berupa konsep pemasaran secara offline maupun online dengan media sosial.

Rencana penyelesaian masalah yang ada pada mitra yaitu merancang desain mesin oven atau pengering krupuk. Selain itu memberi pelatihan merancang konsep pemasaran dengan marketing mix dan merancang STP (Segmentation, targeting, positioning). Juga merancang iklan di media sosial untuk alternatif penjualan produk serta memperluas area pemasaran.

Tabel 1. Rencana Penyelesaian Masalah

\begin{tabular}{lll}
\hline \multicolumn{1}{c}{\begin{tabular}{c} 
No. \\
\multicolumn{1}{c}{ Mitra } \\
Permasalahan
\end{tabular}} \\
\hline 1 & $\begin{array}{l}\text { Aspek } \\
\text { Produksi }\end{array}$ & $\begin{array}{l}\text { Merancang desain mesin oven } \\
\text { pengering krupuk puli. }\end{array}$ \\
\hline 2 & $\begin{array}{l}\text { Aspek } \\
\text { manajemen } \\
\text { perencanaan } \\
\text { bahan baku }\end{array}$ & $\begin{array}{l}\text { Merancang perencanaan bahan baku } \\
\text { dengan perhitungan MPS dan MRP. }\end{array}$ \\
\hline 3 & $\begin{array}{l}\text { Aspek } \\
\text { Manajemen } \\
\text { pemasaran }\end{array}$ & $\begin{array}{l}\text { Merancang konsep marketing mix 4P } \\
\text { (Product, Price, Place, Promotion), } \\
\text { STP (Segmentation, targeting, } \\
\text { positioning), dan iklan online di } \\
\text { media sosial. }\end{array}$ \\
\hline
\end{tabular}

Menurut Orlicky (2004) Material Requirement Planning (MRP) merupakan suatu teknik atau prosedur logis untuk menterjemahkan Jadwal Induk Produksi atau Master Production Sheduling (MPS) dari barang jadi atau end item menjadi kebutuhan bersih untuk beberapa komponen yang dibutuhkan untuk menerapkan MPS. Menurut I Nyoman Yuda, (2003) tujuan MRP yaitu meminimalkan persediaan, mengurangi resiko keterlambatan produksi atau pengiriman, komitmen yang realistis, meningkatkan efisiensi.

Marketing mix merupakan sebuah perangkat yang terdiri dari produk, harga, promosi hingga distribusi. Dimana dalam marketing mix tersebut di dalamnya akan sangat menentukan tingkat keberhasilan pemasaran, dan semuanya tersebut dimaksudkan untuk mendapatkan respon yang diperlukan dari pasar yang menjadi sasaran (Selang, 2013). Sedangkan iklan online merupakan sarana promosi produk yang cepat yang mengakibatkan produk mudah dengan cepat dikenal konsumen dan memiliki jangkauan pemasaran yang luas (Medah, 2016).

Pengembangan metode penyelesaian masalah pada mitra yaitu dengan merancang desain alat TTG pada proses penjemuran dengan cara melakukan interaksi dengan mitra saat melakukan desain agar alat tersebut sesuai dengan keinginan pengrajin krupuk puli. Kemudian untuk penyelesaian masalah pada manajemen perencanaan bahan baku dapat dikembamgkan melalui pembuatan MPS dan MRP yang sederhana yang cocok untuk pengrajin. Sedangkan untuk masalah manajemen pemasaran yaitu dikembangkan dengan metode pembuatan marketing mix dengan menentukan $4 \mathrm{P}$ dan juga STP serta pengunaan media sosial untuk pemasaran online.

\section{METODE}

Metode yang digunakan dalam menyelesaikan permasalahan mitra kegiatan pengabdian pada masyarakat pada pengrajin krupuk puli yaitu (1) permasalahan pertama pada proses penjemuran krupuk dilakukan perancangan desain mesin oven atau pengering krupuk yang ergonomis dengan teknik diskusi dengan mitra saat menentukan desain. Kemudian pada penyelesaian permasalahan kedua (2) yaitu pada manajemen perencanaan bahan baku dilakukan dengan cara memberikan pelatihan dan pendampingan pembuatan MPS dan MRP yang sederhana agar memudahkan mitra dalam pembautannya. Pada penyelesaian permasalahan ketiga (3) yaitu pada manajemen pemasaran dilakukan pelatihan dan pendampingan merancang konsep marketing mix dan membuat iklan online di media sosial.

\section{HASIL DAN PEMBAHASAN}

\section{Perancangan Desain Mesin Oven Pengering Krupuk}

Pada proses penjemuran mitra selama ini memanfaatkan panas sinar matahari selama 7-8 jam

$$
\text { Teknologi Tepat Guna }
$$


atau sekitar jam 07:00-14:00. Tentunya hal tersebut akan optimal jika pada musim kemarau saja.

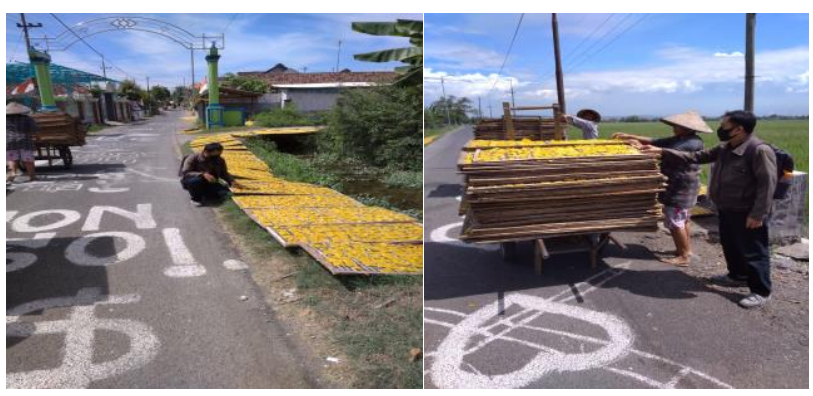

Gambar 1. Proses Penjemuran Krupuk

Bila melihat kondisi proses penjemuran saat ini hanya efektif saat musim kemarau dan akan menjadi masalah saat musim hujan. Maka dari itu penyelesaian masalah tersebut dengan melakukan perancangan desain alat TTG berupa desain mesin oven pengering krupuk. Kegiatan ini dilakukan dengan diskusi dan wawancara dengan pengrajin krupuk puli. Kegiatan dan wawancara tersebut dimaksudkan untuk mendapatkan desain yang sesuai keingginan mitra mulai dari spesifikasi hingga dimensi ukuran mesin.

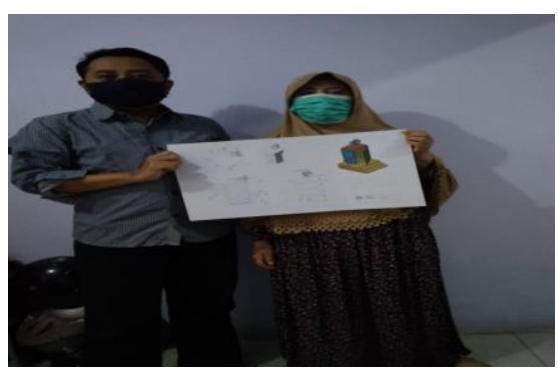

Gambar 2. Proses Penyerahan Desain Mesin Oven

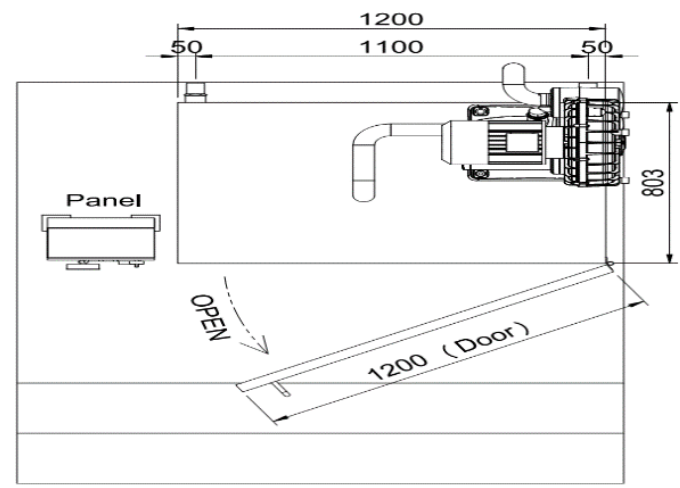

Gambar 3. Desain Mesin Oven Krupuk Tampak Atas

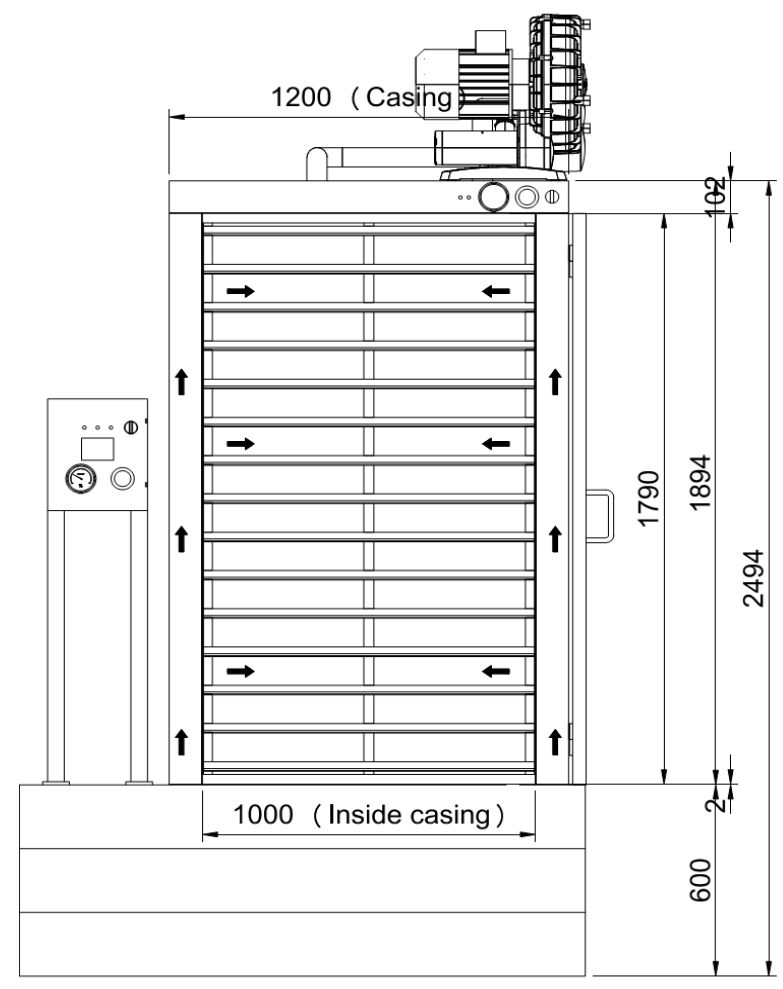

Gambar 4. Desain Mesin Oven Krupuk Tampak Depan 


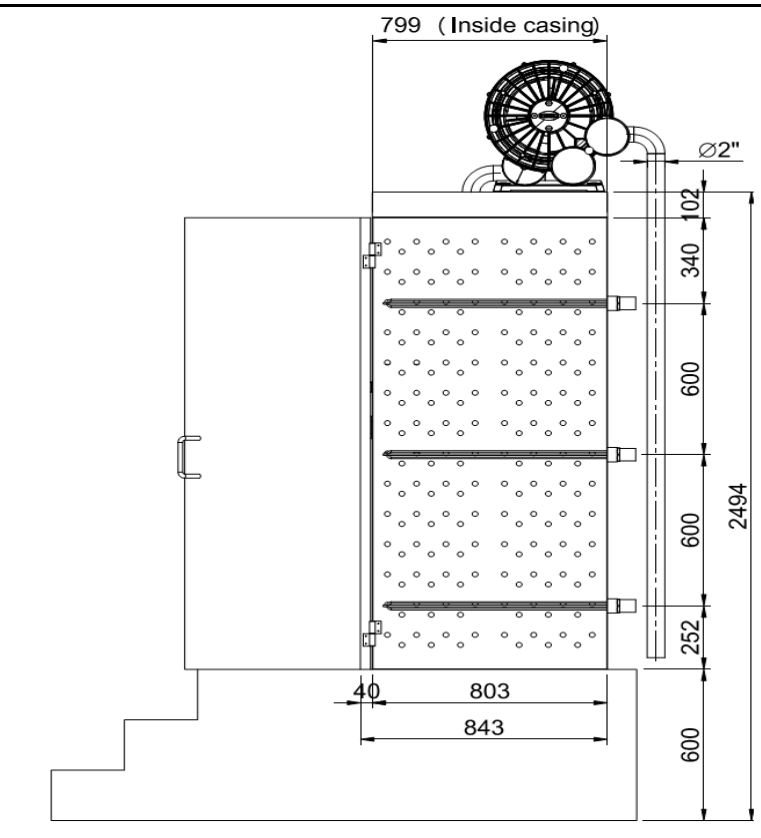

Gambar 5. Desain Mesin Oven Krupuk Tampak Samping

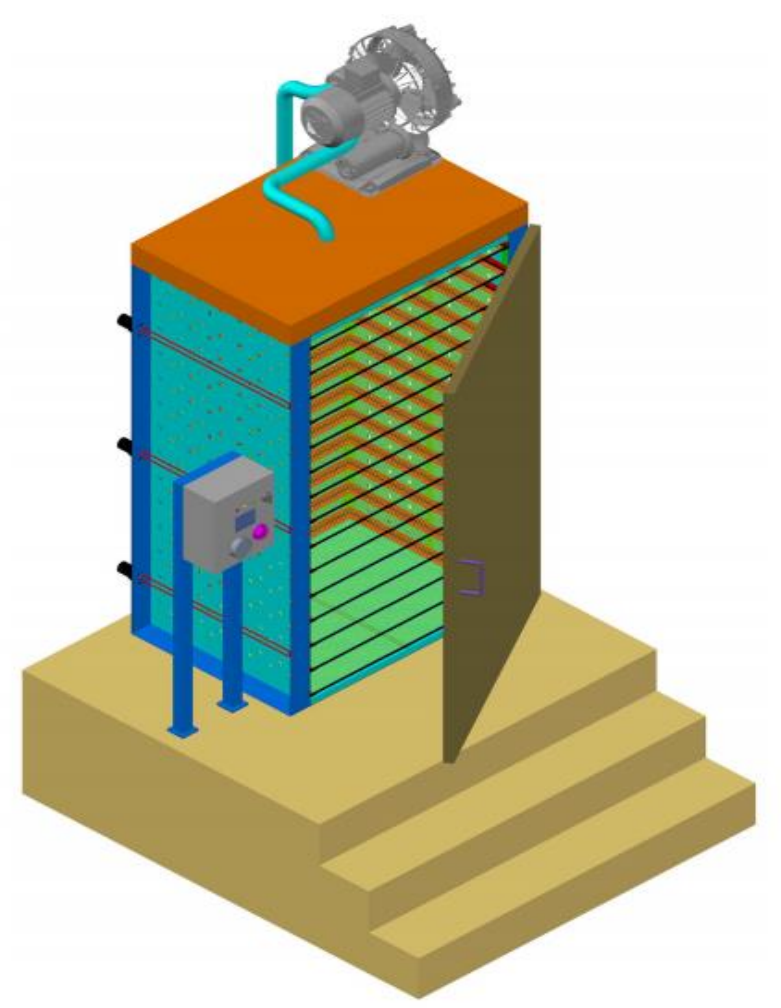

Gambar 6. Desain Mesin Oven Krupuk Tampak 3D

\section{Hasil Pelatihan Membuat Perencanaan Bahan Baku}

Pelatihan membuat perencanaan bahan baku dilakukan agar setiap pengadaan bahan baku yang dilakukan oleh mitra terencana dengan baik. Sehingga hal tersebut agar tidak terjadi pembelian yang memdadak dan juga biaya pembelian bahan baku menjadi efisien. Pada pelatihan ini mitra di latih untuk membuat perencanaan bahan baku yang di mulai dengan menentukan jadwal produksi dengan MPS dan kebutuhan material dengan MRP per bulan.

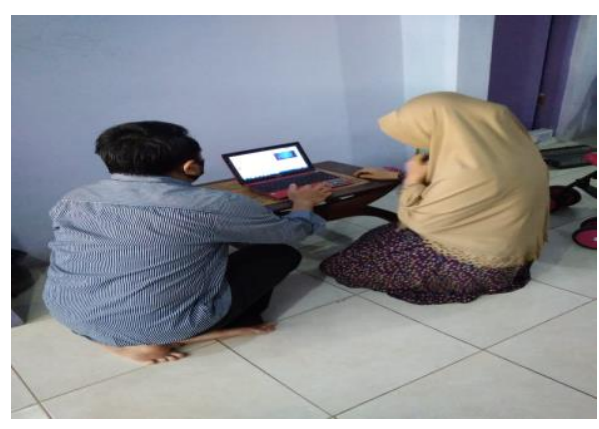

Gambar 7. Pelatihan membuat perencanaan Bahan baku

Tabel 2. Contoh Hasil Pelatihan Membuat Perencanan Kebutuhan bahan Baku

\begin{tabular}{cccc}
\hline No & Bulan & $\begin{array}{c}\text { MPS } \\
\text { (Kwintal) }\end{array}$ & $\begin{array}{c}\text { MRP } \\
\text { (Kwintal) }\end{array}$ \\
\hline 1 & Agustus & - & 100 \\
\hline 2 & September & 100 & 110 \\
\hline 3 & Oktober & 110 & 100 \\
\hline 4 & November & 100 & 90 \\
\hline 5 & Desember & 90 & 80 \\
\hline 6 & Januari & 80 & 120 \\
\hline 7 & Februari & 120 & - \\
\hline
\end{tabular}

\section{Hasil Pelatihan Merancang Konsep Pemasaran}

Pelatihan merancang konsep pemasaran untuk mitra dilakukan untuk meningkatkan penjualan dan juga penjualan lebih tepat sasaran serta memiliki jangkauan pemasaran yang lebih luas. Selain itu juga agar mitra tidak hanya tergantung dengan pesanan dari para tengkulak yang datang ke rumah. Pada kegiatan ini mitra dilatih untuk membuat konsep pemasaran secara 
offline dengan metode marketing mix 4P dan STP. Serta dilatih membuat iklan online di media sosial.

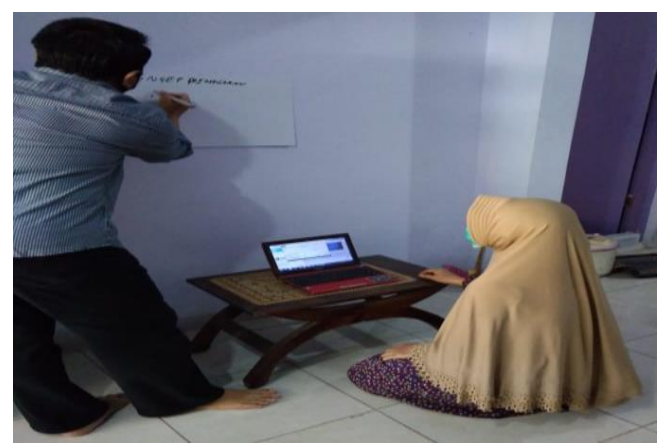

Gambar 8. Pelatihan Membuat Konsep Marketing

Tabel 3. Hasil Pelatihan Membuat Marketing Mix

\begin{tabular}{|c|c|c|c|}
\hline Produk & Price & Place & Promotion \\
\hline $\begin{array}{l}\text { Ukuran } \\
5 \mathrm{Kg}\end{array}$ & 50.000 & $\begin{array}{l}\text { Toko besar \& } \\
\text { Agen }\end{array}$ & $\begin{array}{c}\text { Kerjasama \& } \\
\text { Media sosial }\end{array}$ \\
\hline $\begin{array}{l}\text { Ukuran } \\
1 \mathrm{~kg}\end{array}$ & 10.000 & $\begin{array}{l}\text { Toko oleh-oleh } \\
\text { \& pasar }\end{array}$ & $\begin{array}{l}\text { Kerjasama \& } \\
\text { Media sosial }\end{array}$ \\
\hline
\end{tabular}

Tabel 4. Penentuan STP

\begin{tabular}{llll}
\hline Ukuran & Segmentation & Targetting & $\begin{array}{l}\text { Positio } \\
\text { ning }\end{array}$ \\
\hline $\begin{array}{l}\text { Kemasan } \\
5 \mathrm{Kg}\end{array}$ & $\begin{array}{l}\text { Tegkulak, agen, } \\
\text { supllier }\end{array}$ & $\begin{array}{l}50 \mathrm{Kg} \text { per } \\
\text { hari }\end{array}$ & $\begin{array}{l}\text { Isinya } \\
\text { lebih } \\
\text { banyak }\end{array}$ \\
\hline $\begin{array}{l}\text { Kemasan } \\
1 \mathrm{Kg}\end{array}$ & $\begin{array}{l}\text { Toko oleh- } \\
\text { oleh, ibu } \\
\text { rumah tangga }\end{array}$ & $\begin{array}{l}\text { 30 Kg per } \\
\text { hari }\end{array}$ & $\begin{array}{l}\text { Kemas } \\
\text { an lebih } \\
\text { praktis }\end{array}$ \\
\hline
\end{tabular}




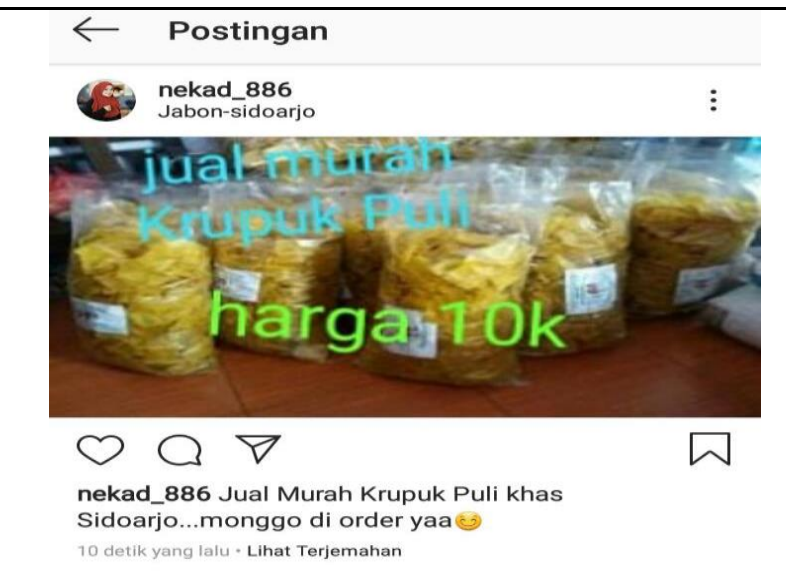

Gambar 9. Contoh Iklan Online Krupuk Puli

\section{KESIMPULAN}

Berdasarkan kegiatan pengabdian dapat disimpulkan bahwa penggunaan mesin oven pengering krupuk puli diharapkan dapat meningkatkan kapasitas produksi per hari karena waktu proses pengeringan bisa lebih cepat karena kapasitas $25 \mathrm{Kg}$ per 60 menit atau 1 jam. Pelatihan perencanaan bahan baku dijharapkan mitra mampu merancang suatu rencana pembelian yang sesuai dengan pesanan agar pembelian bahan baku lebih efektif dan ekonomis. Sedangkan untuk pelatihan pemasaran diharapkan mampu meningkatkan penjualan dan mitra telah terbiasa membuat perencanaan pemasaran dengan baik dan benar.

\section{UCAPAN TERIMAKASIH}

Setelah berakhirnya kegiatan ini, maka kami ucapkan terima kasih kepada :

1. Ketua LPPM Universitas Wijaya Putra Surabaya.

2. Dekan fakultas Teknik Universitas Wijaya Putra Surabaya.

3. Ketua Program Studi Teknik Industri Universitas Wijaya Putra Surabaya.

\section{REFERENSI}

Bayu. (2013). Kampung Kerupuk Kedung Rejo, wisatasidoarjo.com, Dikases 28 Maret 2020, http://www.wisatasidoarjo.com/kampung-kerupukkedung-rejo/.
I Nyoman Yudha Astana. (2003). Perencanaan Persediaan Bahan Baku Berdasarkan Metode Material Requirement Planning.

Kotler \& Keller. (2009). Manajemen Pemasaran. Jilid I Edisi Ke 13 jakarta: Erlangga.

Medah Melgiana. (2016). E-commerce Sebagai Pendukung Pemasaran Perusahaan, Program Studi Manajemen Agribisnis Politeknik Pertanian Negeri Kupang, Jurnal PARTNER, Tahun 2016 Nomor 1, Halaman 74-81.

Moniharapon, S., Oroh, Sem G., \& Ie, Herlin., (2015). Penerapan Strategi Promosi Pada Pemasaran Produk Federal Parts CV. Kanaka Jaya Manado, Jurnal EMBA, Vol.3 No.2 Juni 2015, Hal. 650-659.

Muhi Hanapiah A. (2009). Teknologi Tepat Guna (TTG) Dalam Perspektif Pemberdayaan Masyarakat, Institut Pemerintahan Dalam Negeri (IPDN),Jatinangor,alimuhi.staff.ipdn.ac.id/wpconte nt/.../01/TTG-dan-Pemberdayaan-Masyarakat1.pdf.

Nurmianto Eko. (2018). Pentingnya Ergonomi Teknologi Tepat Guna Di Bidang Industri,, http://tbmkopel.or.id, diakses 20 Agustus 2020, http://tbmkopel.or.id/2018/01/06/ekonurmianto-pentingnya-ergonomi-teknologi-tepatguna-di-bidang-industri/.

Orlicky J. (2004). Material Requirement Planning, Mc Graw - Hill.

Selang A.D Christian. (2013). Bauran Pemasaran (Marketing Mix) Pengaruhnya Terhadap Loyalitas Konsumen Pada Fresh Mart Bahu Mall Manado, Jurnal EMBA 71 Vol.1 No.3, Juni 2013, Hal. 71-80.

Wahyuni, Asvin \& Syaichu Achmad. (2015). Perencanaan Persediaan Bahan Baku Dengan Menggunakan Metode Material Requirement Planning (MRP) Produk Kacang Shanghai Pada Perusahaan Gangsar NgunutTulungagung, Jurnal Spektrum Industri. Vol. 13, No. 2, halaman 115 - 228, ISSN : 1963-6590. 